\title{
ADOLESCÊNCIA NO CONTEXTO DA ESCOLA E DA FAMÍLIA - UMA REFLEXÃO ${ }^{1}$ ADOLESCENCE IN THE FAMILY AND SCHOOL CONTEXTS: A REFLECTION ADOLESCENTE EN EL CONTEXTO DE LAFAMILIAY DE LA ESCUELA-UNA REFLEXIÓN
}

\author{
Maria de Fátima Cardoso Marques* \\ Neiva Francenely Cunha Vieira** \\ Maria Grasiela Teixeira Barroso***
}

\begin{abstract}
RESUMO: A escola é um importante local de aprendizagem acerca da educação para o adolescente, porém não nos esqueçamos de que a família também é fundamental nesse processo, por ser o primeiro lócus de aprendizagem e formação social das pessoas, haja vista a herança cultural passada dos pais para os filhos. Isso tende a ilustrar que os jovens apreendem seus conceitos já no seio da família. Objetivamos refletir sobre a adolescência no contexto da família e da escola diante da velocidade de mudanças nos diversos setores sociais, políticos, econômicos, éticos, entre outros. É um estudo reflexivo sobre os conceitos pertinentes à adolescência. Os conhecimentos dos adolescentes, apreendidos através da sua realidade sociocultural formando seus conceitos, chamamos de "senso comum" e entendemos como fortes influenciadores na vivência da fase, que por sua vez encontra barreiras de comunicação no seio da família. Entendemos que a família é o lócus onde o adolescente vê seus principais exemplos de vida. Refletindo sobre o estudo, consideramos a família e a escola como espaços primordiais na vida dos adolescentes.
\end{abstract}

PALAVRAS-CHAVE: Adolescência; Família; Escola; Sexualidade

\section{INTRODUÇÃO}

Um importante local de aprendizagem acerca da educação sexual para o adolescente é a escola, porém não nos esqueçamos de que a família também é fundamental nesse processo, por ser o primeiro lócus de aprendizagem e formação social das pessoas, haja vista a herança cultural passada dos pais para os filhos. Isso tende a ilustrar que os jovens apreendem seus conceitos já no seio da família.

A escola, por sua vez, está situada dentro de uma gama de fatores sociais, políticos, econômicos, éticos, religiosos, culturais, e muitos outros, que a tornam lerda e lenta para acompanhar a velocidade de mudanças da sociedade pós-moderna ${ }^{(1)} \mathrm{em}$ relação aos adolescentes. Visto que cada pessoa vem de um diferente meio e tem maneiras diversas de entender um mesmo conceito em virtude das imagens e noções que variam de pessoa para pessoa, considerando as especificidades de cada um ${ }^{(1)}$.

No caso dos adolescentes não é diferente. Entendemos que muitos problemas da população jovem estão em torno da sua exposição a riscos, drogas, álcool, iniciação precoce, gravidez na adolescência. Estas situações têm-se acentuado desde a liberação sexual que a sociedade pós-industrial trouxe para a atualidade ${ }^{(2)}$, e ainda as dificuldades de comunicação na família.

Extraído da Dissertação de Mestrado “ Adolescência e sexualidade - educação em saúde para o autocuidado”, apresentada em 2003 à Pós-graduação em Enfermagem da Universidade Federal do Ceará.

* Enfermeira graduada pela Universidade Estadual do Ceará. Mestra em Saúde da Comunidade pela Universidade Federal do Ceará. Trabalha no PSF de Fortaleza

** PhD pela Universidade de Bristol - Inglaterra

*** Professora Emérita, Titular, Docente Livre da FFOE/ Universidade Federal do Ceará. Pesquisadora do CNPq. Projeto Educação em Saúde no Contexto da Promoção Humana - uma investigação na enfermagem. 
Acrescentamos que é fundamental ajudar os adolescentes na compreensão e vivência dessa fase para a vida adulta, valorizando-os como sujeitos da sua história, destacando a família e a escola como espaços primordiais na formação de opinião desses sujeitos em direção à promoção da saúde. No presente estudo objetivamos refletir sobre a adolescência no contexto da família e da escola diante das aceleradas mudanças nos diversos setores sociais, políticos, econômicos, éticos, entre outros. É um estudo reflexivo sobre conceitos pertinentes à adolescência.

\section{REFLEXÃO DOS CONCEITOS PERTINENTES}

Adolescência é o período da vida humana que começa com a puberdade e tem como característica principal as mudanças corporais e psicológicas, compreendida na faixa etária dos 12 aos 20 anos. . $^{(3,4)}$

A adolescência é também uma fase de mudanças biológicas, que acontece para alguns, já a partir dos 11 anos, por influência hormonal. Essa produção de hormônios acontece quando o cérebro (hipotálamo) envia mensagens para a hipófise que secreta os hormônios luteotrófico nos meninos e o folículo estimulante nas meninas; agem através da corrente sangüínea, respectivamente nos testículos e nos ovários. Logo começam a aparecer as características sexuais secundárias nos meninos e nas meninas. Nos meninos aparecem pêlos na região pubiana, a voz se altera e já começa a ocorrer ejaculação. Nas meninas surge a primeira menstruação (menarca) e o corpo vai tomando formas mais arredondadas. Nesta fase, já pode acontecer a geração de filhos, caso haja uma relação sexual sem uso de contraceptivo(5).

O conceito de adolescência está difundido no mundo e de acordo com o Fundo de Populações das Nações Unidas, surgiu com a industrialização e o crescimento das cidades urbanas no século XVII(5).

Um dos conceitos mais antigos apresentado por Aristóteles, na Grécia Antiga, ao referir-se aos adolescentes como: Apaixonados, irascíveis, capazes de serem arrebatados por seus próprios impulsos ${ }^{(6)}$... Mas o fato é que tal conceito tem se ampliado.

O adolescente é um ser biológico, animal, social, situado no real, totalmente humano, cheio de sonhos, expectativas, ansiedades, necessidades, crenças, valores, conhecimentos, temores, tristezas, alegrias e energias peculiares. É um ser coletivo, afinal está inserido num macro sistema interativo em que a sua visão se transforma de acordo com a dinâmica das interações com o meio social. Reforçamos a idéia da compreensão dos diversos contextos biopsicossociais por que passam o adolescentes e os jovens ${ }^{(7)}$.

Talvez em razão das próprias características da fase, eles sejam tão vulneráveis. Do ponto de vista psicológico, essa vulnerabilidade é percebida nas seguintes características: onipotência pubertária; necessidade de buscar o novo; transgredir; dificuldade de escolher; conflito entre razão e sentimento(negação); urgência temporal; dificuldade de administrar esperas; suscetibilidade a pressões grupais e à moda; dependência econômica; medo de se expor; insegurança; elaboração fantasiosa das primeiras atividades sexuais ${ }^{(8)}$.

Nas idas e vindas do desenvolvimento do adolescente, convém também ressaltar outro aspecto a ser considerado: o senso de pertença (grupo de pares). Segundo os estudiosos do ser adolescente, este é um sentimento decorrente da necessidade que ele tem de identificação e aceitação com um determinado grupo, no qual deseja inserir-se. A razão de escolha do grupo pode variar desde o estilo de vestir até outros modos de identificação, como a fala e os gestos que variam de acordo com o seu momento atual. $O$ adolescente faz isso para se sentir pertencente ao mundo e melhorar a auto-estima ${ }^{(8)}$.

As diferenças de gênero, também são visíveis no processo de amadurecimento dos meninos e meninas. As meninas geralmente amadurecem mais cedo, são vistas como sendo mais emocionais. Já os meninos são criados para serem mais racionais, machões. Dessa forma, percebemos como o gênero parece influenciar diretamente na forma dos adolescentes se descobrirem como seres sexuais e no modo de lidarem com a sexualidade ${ }^{(9)}$.

A sexualidade começa a aflorar na mente do jovem, mesmo que ele não tenha vida sexual ativa. Os meninos passam a agir como caçadores, tentam persuadir, conquistar as meninas e estas, no geral, protelam por mais tempo a primeira relação sexual( ${ }^{(10)}$. 
Por outro lado, cada vez mais a iniciação sexual nas adolescentes brasileiras é mais cedo, entre 15 e 17 anos, já nos meninos é de 17 e 18 anos ${ }^{(11)}$.

A preocupação inicial dos adolescentes parece estar na busca de um relacionamento com outro sexo como forma de aceitação e identificação sexual(9).

A formação da identidade do adolescente é importante no estudo sobre sexualidade. A partir de Freud, vários teóricos desenvolveram suas teorias sobre a identidade do adolescente. Um dos mais famosos diz que as personalidades se formam na medida que as pessoas progridem por estágios psicossociais, através da vida. Acrescenta que a busca da identidade revela o porquê de muitos padrões de comportamento do adolescente ${ }^{(12)}$.

De uma forma mais genérica, a sexualidade é estar na vida e de uma forma mais simplista, é como o prazer proporcionado por todo o corpo ${ }^{(13)}$. Reforçamos a crítica de que ela não está restrita à genitália. ${ }^{(13)}$ Complementamos que esse entendimento para os adolescentes sobre sexualidade como algo não restrito à genitália, pode ser um importante fator que contribua para a vivência da sexualidade sem riscos. Os adolescentes compreendem a sexualidade como relação sexual, ato biológico ${ }^{(14)}$. Daí a relação sexual acontece entre os jovens sem levar em consideração a afetividade. Antes esta deve ser discutida, ampliando o conceito de sexualidade, a qual representa, para muitos, apenas o ato sexual em si(15).

Os conhecimentos dos adolescentes, apreendidos através da sua realidade sociocultural formando seus conceitos, chamamos de "senso comum" e entendemos como fortes influenciadores na vivência da sexualidade, que por sua vez encontra barreiras de comunicação no seio da família. Entendemos que isso tem afetado a educação dos pais aos filhos, e, como estes são seres que não nasceram prontos, acabam sendo o resultado de todo um mundo passado que transitou para eles através dos adultos ${ }^{(16)}$.

Nesta compreensão podemos dizer que a vivência da sexualidade pelo adolescente é permeada por diversos fatores, tanto sociais (realidade cultural) quanto biológicos (hormonais) e emocionais. Dentro dessa diversidade de acontecimentos, eles se deparam com o ser existencial do processo de adolescer. Esses fatores indicam uma passagem biopsicossocial não somente biológica para a "vida adulta" em torno dos valores culturais apreendidos do meio, principalmente na família. ${ }^{(7)}$

Entendemos que a família é o lócus onde o adolescente vê seus principais exemplos de vida. Geralmente o menino se vê no pai e a menina se espelha na mãe ou naquela pessoa que para ele ou ela é um referencial de vida porque convivem diariamente com eles. Desse modo, os adolescentes podem ser influenciados positiva ou negativamente ${ }^{(9)}$.

A família, mais do que ninguém, educa todo dia, toda hora, sendo a instância mais responsável pelas condições de emancipação das decisões dos filhos ${ }^{(17)}$.

A comunicação familiar é fundamental na socialização do adolescente ${ }^{(18)}$, pois é no ambiente social da família que esse processo se inicia e onde ele forma suas primeiras opiniões. Neste sentido a família é o local principal de formação do caráter de uma pessoa e o canal de comunicação deve ser bem desenvolvido por esta, para que haja inter-relação e conseqüentemente segurança de aceitação e compreensão do jovem sobre o seu meio, principalmente pela necessidade de maior atenção da família na educação sexual dos filhos ${ }^{(18)}$. $O$ significado da educação sexual na relação pais e adolescentes, é considerada difícil por estes, entretanto, sobre outros assuntos, os pais são ótimos, haja vista que sobre sexualidade continuam omissos, no sentido de não conversarem abertamente sobre isso ${ }^{(19)}$.

A família deve focalizar no diálogo (entendimento) as estratégias de ajudar os adolescentes para que possam lidar com a sexualidade de forma saudável e livre de riscos, não se esquecendo de que o diálogo, é apenas um aspecto da comunicação.

Existem várias formas facilitadoras em um processo de comunicação, os quais, quando empregadas corretamente, ajudam na compreensão do cotidiano do adolescente e concordamos com a autora. Estas formas são reflexão de sentimentos: aprender a sintonizar; auto-expressão: dizer o que sentimos; confronto: a 
aprendizagem das conseqüências e colocar limites: o que pode e o que não pode, sendo a principal delas a reflexão de sentimentos e da qual dependem todas as outras. Isto porque é um modo excelente de tentar entrar em sintonia com o mundo interior de uma pessoa e, dessa forma, poder transmitir aceitação e compreensão ${ }^{(10)}$. Todas essas formas de comunicação estão diretamente relacionadas como a auto-estima, motivação e vontade dos adolescentes para compreenderem sua fase e, por conseguinte serem compreendidos, se aceitarem e serem aceitos com os menores conflitos possíveis.

A auto-estima dos filhos é muito importante. Esta tem como definição a maneira pela qual uma pessoa se sente em relação a si mesma. É o quanto a pessoa gosta de si mesma, um sentimento do próprio valor ${ }^{(21)}$; ou seja, ou a pessoa se dá um alto valor (alta auto-estima) ou se dá um baixo valor (baixa auto-estima).

Já motivação é o motivo que move uma pessoa a pôr em ação uma idéia, fazendo-a mudar de curso(22). É a vontade de executar ou perseguir uma determinada meta ${ }^{(23)}$. É a faculdade de representar mentalmente um ato que pode ser ou não praticado em obediência a um impulso ou a motivos ditados pela razão. É a capacidade de escolha, de decisão ${ }^{(2)}$. Entendemos que estes conceitos são importantes para quem lida com adolescentes na escola e na família, pois ajudam na compreensão destes como sujeitos que desejam e tomam de decisões numa fase de descobertas e mudanças e, portanto, necessários para minimizar os conflitos quase sempre presentes.

Reiteramos, portanto, a importância de ajudar os adolescentes a vivenciarem e lidarem com este momento, de forma prazerosa para não trazer prejuízos tanto para sua saúde. A família e a escola são fundamentais na promoção da saúde do adolescente, criando e implementando estratégias conjuntas de apoio, conhecimento, habilidades e atitudes, de forma que os adolescentes se sintam compreendidos como sujeitos. Esse é um processo que acontece a longo prazo. E se tiver características de dominação e opressão não produzirá resultados em tempo e espaços almejados ${ }^{(24)}$.

\section{CONSIDERAÇÕES FINAIS}

Refletindo sobre o estudo, consideramos a família e a escola como espaços primordiais na vida dos adolescentes. O primeiro, por ser o lócus inicial de formação de seus membros, repassa geralmente as características dos seus lares passados e, portanto, podem torná-los repetidores e não agentes da sua história. Da família são herdados conceitos que muitas vezes trazem prejuízos para a vida adulta e que tendem a se repetir no futuro. Esses conceitos estão ligados às mais diversas áreas, advindos de uma "educação" repressora em face dos questionamentos característicos da adolescência. Neste sentido, consideramos que a família é a instância primária responsável por estabelecer vínculos de comunicação com seus agregados para torná-los críticos, reflexivos e problematizadores na tomada de decisões.

Por sua vez, a escola é uma parceira fundamental na continuidade da formação de opinião consciente dos adolescentes acerca do seu meio, porque esta agrega pessoas que estão em processo de aprendizagem e, portanto, flexíveis ou passíveis de mudanças ou revisão de seus hábitos. Para a compreensão desse fato, se faz necessários trabalhos de conscientização contínuos e sistemáticos que envolvam a família e a escola de forma articulada na promoção da saúde dos adolescentes como política nacional de saúde envolvendo profissionais, professores e família.

ABSTRACT: The school is an important place of learning about education to adolescents. However, we cannot forget that the family is also fundamental in this process. It is the first learning and social formation locus of people, if we consider the cultural inheritance children receive from their parents. This fact tends to illustrate that young people apprehend their concepts already in the family circle. We objectify to reflect about adolescence in the family and school contexts considering the speed of changes in several social, political, economic and ethic sectors, among others. It is a reflexive study about the concepts pertinent to the adolescence. 
The adolescents' knowledge, which is apprehended through their sociocultural reality that forms their concepts, is called "common sense". We understand it as a strong influence on the experience of this phase, which, in its turn, face communication barriers in the family circle. We understand the family as the locus where the adolescent finds their main examples of life. After reflecting about this study, we consider the family and the school primordial spaces in the adolescents' lives.

KEY-WORDS: Adolescence; Family; School; Sexuality

RESUMEN: La escuela es un importante sitio de aprendizaje quando se trata de la educación del adolescente, pero no nos olvidemos que la familia es fundamental en ese proceso, siendo el primer locus de aprendizaje y formación social de las personas, ya que es la herencia cultural que pasa de padres para hijos. Esto demuestra que los jóvenes adquieren sus conceptos desde el seno de la familia. Objetivamos reflexionar sobre la adolescencia en el contexto de la familia y de la escuela delante de la rapidez de las mudanzas en los diversos sectores sociales, políticos, económicos, éticos, entre otros. Es un estudio reflexivo sobre los conceptos pertinentes a la adolescencia. Los conocimientos de los adolescentes, retenidos a través de su realidad sociocultural formando sus conceptos, llamamos de "senso común" y entendimos como fuerza influenciadora en la vivencia de esta fase, que por su vez encuentra barreras de comunicación en el seno de la familia. Entendimos que la familia es el locus donde el adolescente ve sus principales ejemplos de vida. Reflexionando sobre el estudio, consideramos la familia y la escuela como espacios primordiales en la vida de los adolescentes.

PALABRAS-CLAVES: Adolescencia; Familia; Escuela; Sexualidade

\section{REFERÊNCIAS}

1. Gomes JB, Casagrande LDR. A Educação reflexiva na pós-modernidade: uma revisão bibliográfica. Rev. Latino-am Enferm 2002; 10(5): 696-703.

2. Graham G. Youht health promotion in the community. In: Community health promotion. Challenges for pratice. London: Baillière Tindall; Royal College of Nursing; 2000.

3. Ferreira ABH. Miniaurélio século xx: escolar Minidicionário da língua portuguesa. Rio de Janeiro: Nova Fronteira; 2000.

4. Ministério da Saúde (BR). Secretaria Nacional de Programas Especiais de Saúde Materno-Infantil. Programa de Saúde do Adolescente. Bases programáticas. Brasília, 1989.

5. Secretaria do Trabalho e Ação Social (Ceará). Fundo de Populações das Nações Unidas - FUNAP. Projeto Amor à Vida. Manual do multiplicador: discriminação e homossexualidade. Fortaleza; 1997a.

6. Günther IA. Apud Aristóteles. Adolescência e projeto de vida. In: Brasil, Ministério da Saúde - Secretaria de Políticas de Saúde Área de Saúde do Adolescente e do Jovem. Volume I Cadernos Juventude, Saúde e Desenvolvimento. Brasília, agosto de 1999. 300p.

7. Patrício ZM. O Cuidado com a qualidade de vida dos adolescentes: um movimento ético e estético de "Koans e Tricksters". In: Ramos FRS; Monticelli M., Nitschke RG, organizadores. Projeto Acolher: Um Encontro da Enfermagem com o adolescente brasileiro. Brasília: ABEn/ Governo Federal, 2000. 196p.

8. Cavasin S, Arruda S. Adolesci. E Agora?. In: Prevenir é sempre melhor. Coordenação Nacional de DST e aids. Brasília: Ministério da Saúde, Coordenação Nacional de DST e Aids, 1998. 102 p.

9. Secretaria do Trabalho e Ação Social (Ceará). Fundo de Populações das Nações Unidas - FUNAP. Projeto Amor à Vida. Manual do multiplicador: entendendo a adolescência. Fortaleza, 1997b.

10. Maldonado MT. Comunicação entre pais e filhos. A Linguagem do sentir. 19 ed. São Paulo: Saraiva; 1995.

11. Vitiello N. Disponível em: http:/www.sosdoctor.com.br/sossexualidade/iniciação-sexual.asp. Acesso em 01/2003.

12. Erikson. Introdução à psicologia. São Paulo: Makron Books do Brasil; 1983. 
13. Lopes G. Sexualidade humana. 2. ed. Rio de Janeiro: MEDSI; 1993.

14. Marques MFC. Adolescência e sexualidade - educação em saúde para o autocuidado. [dissertação]. Fortaleza (CE): Universidade Federal do Ceará, 2003.

15. Diógenes MAR; Varela ZMV. O Autocuidado da adolescente portadora de doenças sexualmente transmissíveis na vivência da sexualidade. In: Barroso MGT; E Varela ZMV, organizadores. Saúde da família. Abordagem multireferencial em pesquisa. Sobral: Edições UVA; 2002.

16. Cortella MS. Adolescência e transgressão: quem é a vítima da nossa ilusão de ética?. In: Pinto T; Telles IS, organizadores. Aids e escola. Reflexões e propostas de EDUCAIDS. 2. ed. São Paulo: Cortez; UNICEF; 2000.

17. Demo P. Educar pela pesquisa. 2. ed. São Paulo: Autores associados; 1997.

18. Ribeiro M A. Comunicação familiar e prevenção de DST's/aids entre adolescentes. J Brás Doenças Sex Transm. 1998; $10(1)$ : 5-9.

19. Jesus MCP. O Significado da educação sexual na relação pais/adolescentes. Rev Bras Enferm 1999; 52(3): 455-68.

22. Boruchovitch E; Bzuneck J A, organizadores. A Motivação do aluno. Contribuições da psicologia contemporânea. Petrópolis: Vozes; 2001.

21. Briggs DC. A Auto-estima do seu filho. 2. ed. São Paulo: Martins Fontes; 2000.

23. Forte BF. Motivação no trabalho em saúde: uma cultura de conflitos e resistências. In: Forte, BF; Fraga MNO; Guedes MVC. Cultura e poder nas políticas públicas: Prática clínica e social aplicada. Fortaleza: Pós-graduação/DENF/UFC; 1998.

24. Pinto TCR. Por um modelo libertador. In: Pinto T; Telles IS, organizadores. Aids e escola. Reflexões e propostas de EDUCAIDS. 2. ed. São Paulo: Cortez; Pernambuco: UNICEF; 2000.

Recebido em 28/11/2002 aceito em 03/03/2003 